Process: What is the best way of identifying parents' learning needs/preferences? Using a structured questionnaire or a semistructured discussion?

Outcome: How can information about parents' learning needs/preferences be used? Are professionals able and willing to adjust their practice to meet parents' needs?

Conclusions Though professionals may develop an understanding of how to support parents' learning over time, they can sometimes misjudge parents' needs. Therefore, parents should routinely be asked about their learning needs/preferences. The PLAnT could be used to identify these needs, though further refinement, piloting and feasibility testing is required in future research to address the questions raised by the current study.

\section{G42 A QUALITATIVE STUDY EXPLORING THE ATTITUDES OF ACUTE CARE CHILDREN'S NURSES ON OPPORTUNISTIC HEALTH PROMOTION IN OVERWEIGHT CHILDREN}

${ }^{1,2} \mathrm{~N}$ Greenwood, ${ }^{1} \mathrm{~K}$ Lewis. ${ }^{1} \mathrm{Health}$ and Human Sciences, University of Huddersfield, Huddersfield, UK; ${ }^{2}$ Children's Ward, Calderdale and Huddersfield NHS Trust, Halifax, UK

10.1136/archdischild-2015-308599.42

Background Childhood obesity is a national and global issue within public health and continues to be a priority for the Department of Health. Childhood obesity poses a significant risk to psychological and physical health, both now and in the future. The NHS Future Forum set out a vision for all health care professionals to 'make every contact count' by delivering health promotion strategies.

Aim To explore the attitudes of children's nurses about delivering health promotion to overweight children and their families during hospital admissions.

Method A qualitative study, based on semi-structured interviews, involving six children's nurses from a UK based NHS funded hospital. Interviews were recorded and transcribed, from these transcripts thematic analysis was performed

Findings Six themes emerged from the data i) responsibility for delivery of health promotion, ii) sensitivity of the issue, iii) benefits of health promotion iv) influence of parents, v) skills of the nurses and vi) institutional support. The children's nurses perceived their priority for the children in their care was the treatment of the child's illness and that the acute care setting was not the appropriate environment to deliver health promotion. Length of experience and training did not affect the attitudes reported.

Conclusions Childhood obesity is a serious issue demanding action from health care services and the professionals involved. Nurse in acute care settings do not perceive health promoting in relation to obesity is within their scope of practice. Further research is required to facilitate the development of ethical policies on the delivery of health promotion strategies within the acute care setting.

\section{\begin{tabular}{|l|l} 
G43 TEACHING FOR LIFE PROJECT \\
\hline
\end{tabular}}

${ }^{1} \mathrm{~K}$ Summers, ${ }^{2} \mathrm{~S}$ Robinson, ${ }^{3} \mathrm{I}$ Durrant, ${ }^{3} \mathrm{~A}$ Ekins, ${ }^{3} \mathrm{H}$ Jones. ${ }^{1}$ School of Nursing, Canterbury Christ Church University, Canterbury, UK; ${ }^{2}$ School of Public Health, Canterbury Christ Church University, Canterbury, UK; ${ }^{3}$ School of Education, Canterbury Christ Church University, Canterbury, UK

10.1136/archdischild-2015-308599.43
Aims There are increasing numbers of children with life limiting (LL) or life threatening (LT) conditions in mainstream schools. Previous research shows that the needs of these children are not being well met. The symptoms of their condition and its treatment can interfere with a child's whole school experience including their learning, their self-esteem and their relationships. Many children and parents feel under supported by schools. In England, the Children and Families Bill (2013) aims to bring about better integration of health care, social care and education for these children. The Teaching for Life project is a collaborative project between the disciplines of Education and Health and Social Care which aimed to explore the needs of teachers in relation to working with children with life limiting or life threatening conditions.

Methods Comprised of an on-line questionnaire to 550 teachers undertaking the Special Education Needs training and teaching staff in mainstream schools who had experience of working with children with life limiting or life threatening conditions. Post the questionnaire a series of focus groups were also undertaken with groups of teachers who had experience and those without.

Results The most common LL/LT condition experienced by teachers was cancer followed by cerebral palsy, Duchennes muscular dystrophy and cystic fibrosis. There was a wide variance across schools about who was responsible for keeping medical and care needs updated. Half of the teachers involved in the study had delivered medical care for a child which had led to high levels of anxiety from teachers re meeting the child's medical needs. There is a need for good multi-disciplinary working around the child.

Conclusions Teachers wanted more information, guidance and emotional support with a whole school approach on emotional health and wellbeing. There is a definitive need for true collaboration and inter professional working to be more effective to meet the needs of teachers and children with LL/LT conditions in main stream schools.

\section{G44(P) ENLISTING PARENTS AS SCREENERS FOR DEVELOPMENT DYSPLASIA OF THE HIP - A REVIEW OF A SELF-CHECK GUIDE}

A Lee, N Doherty, R Dodds, N Davies; Department of Paediatric Orthopaedics, Royal Berkshire Hospitals NHS Trust, Reading, UK

\subsection{6/archdischild-2015-308599.44}

Infants have been screened for developmental hip dysplasia (DDH) since the late 1960's. The recognition of the importance for early identification of the condition has been well documented. However, the changes to the national screening programme in 2008 have reduced the surveillance of DDH following the removal of the 8 month infant hip check, leaving only the 6-8 week hip check as standard.

A self-check guide for DDH has been developed to enlist parents as screeners for the condition. The guide highlights common signs used to alert to the possibility of hip dysplasia or dislocation. The guide was distributed out between 2008-2013 through maternity services and Health Centres. The guide provided parents with information on classic signs associated with DDH which they were asked to check for.

Of those infants referred to our specialist clinic as a result of parental screening, 73\% were "abnormal" of these 33\% went on to treatment with splintage. The mean age of these infants was 5.36 months. $20 \%$ of positive findings were in infants aged 7 month or over at the time seen. None went on to open 
surgery. These patients represented between 5 and 10\% of our overall group of DDH positive patients. If left undiagnosed, they may have gone on to late presentation of hip dislocation requiring surgery as a child or undiagnosed acetabular dysplasia and possible surgical treatment in relatively early adult life.

Therefore we concluded that given the right guidance parents/carers would be ideal screeners to assist in detecting possible later presenting DDH in their baby.

\section{Child Protection Special Interest Group}

\section{G45 WHAT IS THE ASSOCIATION BETWEEN EPISTAXIS AND ASPHYXIATION IN CHILDREN UNDER 2 YEARS? A SYSTEMATIC REVIEW}

P Rees, A Kemp, F Dunstan, B Carter, S Maguire. Institute of Primary Care and Public Health, Cardiff University, Cardiff, UK

\subsection{6/archdischild-2015-308599.45}

Aims Whilst epistaxis is a frequent and trivial finding in most children, it is rare in those aged less than 2 years. Epistaxis has been observed amongst intentionally asphyxiated infants using covert surveillance, although the precise relationship between epistaxis and asphyxia has subsequently been called into question. This systematic review aims to determine the probability of asphyxia amongst young children presenting with epistaxis, and define the clinical characteristics of such children.

Methods An all-language search of published and grey literature across 10 databases from 1900-2014 was conducted with 76 key terms. Searches were supplemented with 'snowballing' techniques including hand searching non-indexed journals, checking articles' references, and correspondence with authors for clarification. Inclusion criteria: high quality studies involving children with epistaxis aged less than 2 years; alive or dead on presentation; adequate confirmation or exclusion of intentional or unintentional asphyxia (upper airway obstruction), using an explicit rank of confirmation of asphyxia and non-asphyxia. Studies of traumatic or pathological epistaxis were excluded. All studies were independently critically appraised and data extracted by two trained reviewers.

The probability of asphyxiation in a young child with epistaxis was estimated in a meta-analysis using a random-effects model and is reported as a proportion with 95\% Confidence Intervals (CI).

Results Of 2549 studies identified, 100 underwent full review, resulting in six included studies, representing 30 children with asphyxia-related epistaxis and 74 non-asphyxia related epistaxis. Meta-analysis was feasible for 4 studies yielding a probability of asphyxiation of 20\% (95\% CI $=13-29 \%)$. Children with asphyxia-related epistaxis were aged 30-684 days and described by 2 comparative cross-sectional studies, 1 casecontrol study, and 3 case series (1 of which was comparative). Live asphyxiated children tended to present unwell with altered skin colour, respiratory difficulty, and chest X-ray abnormalities. There were no associated features described among those dead on arrival.

Conclusion This systematic review defines the probability that epistaxis, in the absence of trauma or medical explanation, may indicate asphyxia in children aged less than 2 years, thus reiterating the importance of full investigation of these children who may be at considerable risk of death.

\section{G46 A CLINICAL PREDICTION TOOL (CPT) TO IDENTIFY MALTREATMENT IN CHILDREN WITH BURNS AND SCALDS}

${ }^{1} \mathrm{AM}$ Kemp, ${ }^{2} \mathrm{~L}$ Hollen, ${ }^{2} \mathrm{D}$ Rea, ${ }^{1} \mathrm{MC}$ Pawlik, ${ }^{1} \mathrm{D}$ Nuttall, ${ }^{2} \mathrm{~A}$ Emond, ${ }^{1} \mathrm{~S}$ Maguire. ${ }^{1}$ Institute of Primary Care and Public Health, Cardiff University, Cardiff, UK; ${ }^{2}$ School of Social and Community Medicine, Bristol University, Bristol, UK

\subsection{6/archdischild-2015-308599.46}

Aims An estimated 10\% of childhood burns arise from neglect or physical abuse. The challenge for emergency department (ED) staff with limited child protection training and a high staff turn over is to recognise these children. The aim of this study is to design an evidence-based CPT to assess the risk of maltreatment in a child who presents to ED with a burn or scald.

Methods Derivation: An evidence-based proforma Burns and Scalds Assessment Tool (BaSAT) was developed from a systematic review of the characteristics of burns or scalds due to maltreatment. Standardised data were collected on 1327 children $<16$ years presenting to EDs in the UK and Ireland (2008-10). A CPT for risk of maltreatment was derived from a logistic regression model of several influential factors for the referral of 112/1327 cases to Social Care, namely; age $<5$ years, known to social services, inappropriate injury explanation, full thickness burn, atypical body location, bilateral symmetry and supervision concerns. Based on the predicted probabilities from the logistic regression, the CPT was adapted into a simple scoring system to grade cases as 'concern'/'no concern' for child maltreatment. Validation: data on children with burns attending four UK EDs were collected prospectively (2013-14) on a revised BaSAT, and the CPT prediction validated against child protection referrals to social services.

Results The validation: Of 789 children (median age 30 months) with burns, 7\% (54) were referred to social services. The CPT classified 19\% (74/389) scalds, and 26\% (104/400) burns as 'concern'. For scalds the sensitivity for identification of children referred to social care was $83 \%$ (95\% CI 59-96\%) and specificity was $84 \%$ (95\% CI $80-88 \%$ ) for scalds; positive likelihood ratio $(\mathrm{LR}+) 5.2$ for non scalds the sensitivity was $81 \%(95 \% \mathrm{CI}$ $64-92 \%)$ and specificity of $79 \%$ (95\% CI 74-83\%) for nonscalds; LR+ 3.9.

Conclusions The CPT shows promise as an aid to clinical decision making in the ED setting. In conjunction with the BaSAT it provides standardised clinical assessment and documentation of children with burns/scalds and a prediction of the likelihood of maltreatment. Its applicability and accuracy will now be tested in an implementation evaluation.

\section{G47 ABSTRACT WITHDRAWN}

\section{G48 A SYSTEM FOR ASSESSING THE RISK OF FEMALE GENITAL MUTILATION (FGM) FOR FEMALE INFANTS BORN TO MOTHERS WHO HAVE UNDERGONE FGM}

A Flower, C Palmer, G Hann. Women and Children's Health, North Middlesex University Hospital, London, UK

\subsection{6/archdischild-2015-308599.47}

Aims To introduce and assess the effectiveness of a questionnaire to examine the level of risk of FGM if a girl is born to a mother who has undergone FGM. 